\title{
Childhood adiposity predicts adult-onset current asthma in females: a $25-y r$ prospective study
}

\author{
J.A. Burgess*, E.H. Walters", G.B. Byrnes*, G.G. Giles`, M.A. Jenkins*, \\ M.J. Abramson ${ }^{+}$, J.L. Hopper* and S.C. Dharmage*
}

ABSTRACT: Few data exist on associations between childhood adiposity and incident asthma in later life. The present authors examined the relationship between childhood body mass index (BMI) and incident asthma beginning in adolescence or in adult life.

All subjects included in the study were participants in the Tasmanian Asthma Survey, a large population-based cohort study, and were asthma free at 7 yrs of age. Weight, height and lung function were measured at 7 yrs of age. Asthma status at 7 and 32 yrs of age was ascertained by questionnaire. Odds ratios were calculated for the association between childhood adiposity, expressed as "overweight" or as BMI z-score quartiles at 7 yrs of age, and asthma development after that age.

In females, but not in males, there was a significant association between adiposity at 7 yrs of age and current asthma at 32 yrs of age that developed after the age of 21 yrs. The association was not explained by childhood lung function or age at menarche. There was no association between adiposity at 7 yrs of age and asthma that developed after that age and remitted at 32 yrs of age in either sex.

Higher body mass index in nonasthmatic young females at 7 yrs of age predicts risk of current asthma developing in adult life.

KEYWORDS: Asthma, body mass index, childhood, lung function, menarche, sex

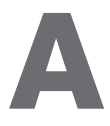
sthma [1-4] and obesity [5, 6] prevalence have risen over recent decades. In the period 1985-1997, the prevalence of overweight and obesity doubled in Australians aged 7-15 yrs [7, 8]. A causal link between obesity and asthma has been suggested but results from earlier studies are inconsistent.

An association between obesity and prevalent asthma was observed in cross-sectional studies in adults [9, 10] and children [11-13]. One study showed a stronger association for females [9] and another observed a stronger association in males, but only for the lowest quartile of body mass index (BMI) [10]. Other studies have not shown any sex difference [11, 13]. Pooled data from seven cross-sectional Australian studies involving Caucasian children [14] showed a significant rising trend across quintiles of BMI for atopy, cough and "wheeze-ever" in young females only but no association with doctor-diagnosed asthma.
Longitudinal studies have supported an association between obesity and incident asthma in children [15] and adults [16, 17]. However, study durations were short. A longitudinal study by CHINN and RONA [18] involving White children showed an association between higher BMI and incident asthma between 5-10 yrs of age. However, CHINN and RonA [18] also suggested that rising asthma prevalence was not explained by rising BMI. A Finnish birth cohort study [19] showed an association between adult obesity developing in normal-weight adolescents and between adolescent obesity persisting into adulthood, and asthma at 31 yrs of age with no sex difference. The comparison group for both analyses consisted of those of normal weight at both ages.

Another cohort study of females [20] showed an association between higher adult BMI and physician-diagnosed incident asthma. A prospective 10-yr study of adults [21] showed an association between the highest quintile of BMI at study
AFFLLIATIONS

${ }^{*}$ Centre for Molecular, Environmental, Genetic and Analytic Epidemiology, University of Melbourne,

- Cancer Council of Victoria, ${ }^{+}$Dept of Epidemiology and Preventive Medicine, Monash University, Melbourne, and \#Respiratory Research Group, University of Tasmania, Hobart, Australia.

\section{CORRESPONDENCE}

J.A. Burgess, Centre for Molecular, Environmental, Genetic and Analytic Epidemiology, University of Melbourne, Level 2, 723 Swanston Street, Carlton, VIC. 3053 Australia. Fax: 61393495815 E-mail: j.burgess@ pgrad.unimelb.edu.au

Received:

June 202006

Accepted after revision:

December 212006

SUPPORT STATEMENT

The Tasmanian Asthma Survey was supported by grants from the Asthma Foundation of Victoria (Melbourne, Australia), the Asthma Foundation of Tasmania Inc. (Hobart, Australia), the Clifford Craig Medical Research Trust (Launceston, Australia), the Royal Hobart Hospital Research Foundation (Hobart, Australia), the University of Melbourne (Melbourne, Australia) the National Health and Medical Research Council of Australia (Canberra, Australia) and Archives Office of Tasmania (Hobart, Australia). Archived data from the 1968 and 1974 surveys were provided by the Archives Office of Tasmania. J. Burgess was supported by a Research Scholarship from the University of Melbourne. G. Byrnes was supported by a National Health and Medical Research Council Capacity Building Grant in Population Health (251533)

Online ISSN 1399-3003 
entry, or an increase in BMI over the study period, and incident asthma only in females. Hormonal factors have been suggested as mediating the association between obesity and higher asthma prevalence [22] or greater asthma severity [23].

These contrasting findings highlight the importance of longitudinal studies spanning from childhood to adulthood in investigating the obesity-asthma association. The Tasmanian Asthma Survey (TAS) is such a study. A longitudinal study using prospectively gathered data on early-life exposure allows the examination of the natural history of asthma and possible causal relationships. In the present paper, an analysis of longitudinal data obtained from the TAS is reported. The main aim was to determine whether BMI at 7 yrs of age (BMI7) was associated with the development of asthma after that age. A further aim was to examine whether any observed associations were modified by sex or explained by childhood lung function and age at menarche.

\section{METHODS}

\section{Study population and data collection}

The TAS began in 1968 when a birth cohort $(n=8,583)$, then aged 7 yrs, was surveyed. Data included height, weight, lung function and a medical history provided by parents (see Appendix 1). Each child's weight and height were measured. Forced vital capacity (FVC), forced expiratory volume in one second (FEV1) and mean forced expiratory flow from $25-75 \%$ of FVC (FEF25-75\%) were measured with a wedge-bellows spirometer (Vitalograph Limited, Maids Moreton, UK). Percentage predicted values were calculated subsequently [24].

A 25-yr follow-up survey was performed in the period 19911993, when a random sample of 2,000 subjects from the birth cohort was selected, stratified by asthma status at 7 yrs of age. Addresses were found for 1,723 (86.2\%) of those selected, who were then sent a respiratory questionnaire. Of these, 1,494 $(87 \%)$ returned a completed questionnaire (see Appendix 2). Participants recorded life history of asthma and atopy-related disorders, and current weight and height. Approximately half (741) presented parent-reported asthma by 7 yrs of age. Those subjects who reported asthma ever at the 25-yr follow-up also recalled their age at asthma onset as "under 7 years", "from 7 to 14 years", "from 15 to 21 years" or "over 21 years". The present report is based on data from the 1968 and 1991 surveys.

\section{Definitions}

"Asthma free by 7 yrs of age" was defined as presenting no history of asthma or wheeze between birth and 7 yrs of age. "Incident asthma after $7 \mathrm{yrs}$ of age" was defined as being asthma free by that age with self-reported asthma by $32 \mathrm{yrs}$ of age. Those individuals who showed incident asthma and suffered an attack within the previous 12 months were classed as having current asthma. Those individuals who showed incident asthma but exhibited no symptoms within the previous 12 months and did not require asthma medication, were classed as having remitted asthma. The comparison group was formed by those individuals who never had asthma by the 25-yr follow-up.

Early menarche was defined as menstruation onset at $\leqslant 11$ yrs of age.
Years of secondary schooling has been validated as a measure of socioeconomic status $[25,26]$ and was used as a surrogate for the socioeconomic status of the family in 1968.

BMI7 was defined as BMI $\left(\mathrm{kg} \cdot \mathrm{m}^{-2}\right)$ at $7 \mathrm{yrs}$ of age, was calculated from measured weight and height, and re-calculated as z-scores against the age- and sex-specific reference standard from the National Centre for Health Statistics [27, 28]. BMI7 overweight was defined by dividing BMI7 into two categories: overweight and normal weight, i.e. above and below the ageand sex-specific cut-points from the reference tables of COLE et al. [29]. BMI at 32 yrs of age (BMI32) was calculated from selfreported height and weight in the $25-y r$ follow-up. It was then grouped into obese, overweight and normal weight categories according to definitions suggested by the World Health Organization [5] and divided into quartiles.

Smoking at 32 yrs of age was a three-level variable that classified individuals as current, former and never-smokers.

\section{Analytical methods}

BMI7 was the independent variable of interest. To avoid obscuring nonlinear dependence on BMI7, the present authors first analysed the data by BMI7 z-score quartile and then estimated a trend across quartiles. It was also hypothesised that only excess childhood weight was associated with asthma at 32 yrs of age. This was tested by analysing the data using the dichotomous variable, BMI7 overweight. Associations between BMI7 and current or remitted asthma were examined.

Multivariable logistic regression [30] was used to assess the associations while adjusting for confounders. A potential confounder was tested on the basis of a possible association between exposure and outcome of interest. The confounder was retained in the model if it changed the estimates by $\geqslant 20 \%$ or if it was considered to be biologically important. A twosided p-value of 0.05 was regarded as significant.

\section{RESULTS \\ Prevalence and incidence of asthma}

Table 1 summarises the characteristics of the 1991-1993 cohort who were asthma free by 7 yrs of age. There were no significant sex differences in the prevalence of allergic rhinitis, infantile or flexural eczema, family history of asthma, parental smoking or secondary schooling for $\leqslant 3$ yrs (data not shown). Similar results were observed in those subjects with a history of asthma by 7 yrs of age (data not shown). However, there was a difference in the proportion of overweight young females $(16.4 \%, \mathrm{n}=48)$ compared with overweight young males $(9.8 \%, n=44)$ with a history of asthma by 7 yrs of age $(\mathrm{p}=0.03)$.

There were three missing values for BMI7 as three children failed to attend the medical examination. They were excluded from the analysis.

Table 2 summarises the distribution of incident asthma after $7 \mathrm{yrs}$ of age by sex and asthma phenotype (current or remitted).

Out of the 753 individuals who took part in the 25-yr follow-up and were asthma free by 7 yrs of age, $81 \quad(10.8 \%$; $95 \%$ confidence interval (CI) 8.5-13.1) had current asthma. A total of 55 subjects $(7.3 \%$; 95\% CI 5.4-9.2) had remitted asthma. 


\begin{tabular}{|c|c|c|c|}
\hline \multirow{2}{*}{$\begin{array}{l}\text { TABLE } 1 \\
\text { Variable }\end{array}$} & \multicolumn{3}{|c|}{$\begin{array}{l}\text { Baseline characteristics of individuals who never } \\
\text { presented asthma or wheeze by } 7 \text { yrs of age }\end{array}$} \\
\hline & Male & Female & $\mathrm{p}$-value \\
\hline Subjects $n$ & 365 & 388 & \\
\hline BMI7 Z-score & $0.49 \pm 0.71$ & $0.53 \pm 0.67$ & 0.42 \\
\hline \multicolumn{4}{|l|}{ BMl7 raw score $\mathbf{k g} \cdot \mathrm{m}^{-2}$} \\
\hline Maximum & 23.49 & 25.02 & \\
\hline Minimum & 13.65 & 13.60 & \\
\hline Mean & 16.52 & 16.68 & 0.14 \\
\hline Variance & 1.90 & 2.39 & 0.015 \\
\hline BMI7 overweight & $40(11.0)$ & $60(15.5)$ & 0.09 \\
\hline FEV 1 at 7 yrs of age $\mathrm{mL}$ & $1387 \pm 209$ & $1291 \pm 204$ & $<0.001$ \\
\hline FEV $1 \%$ pred & $111 \pm 13.5$ & $108 \pm 13.7$ & 0.003 \\
\hline $\mathrm{FVC}$ at 7 yrs of age $\mathrm{mL}$ & $1520 \pm 233$ & $1391 \pm 211$ & $<0.001$ \\
\hline FVC $\%$ pred & $97.8 \pm 12.1$ & $94.8 \pm 11.2$ & $<0.001$ \\
\hline Urticaria & $56(15.5)$ & $81(21.4)$ & 0.04 \\
\hline
\end{tabular}

\section{BMI7 Z-scores, BMI7 overweight and current asthma at 32 yrs of age}

The associations between BMI7 z-scores expressed as quartiles, BMI7 overweight and current asthma that developed at different ages after 7 yrs of age were examined (table 3). No associations were seen in males and only the results for females are presented.

These associations did not change (results not shown) when adjusted for potential confounders, including exclusive breastfeeding in the first 3 months of life, any or all of the proxy measures of childhood atopy (infantile eczema, flexural eczema, urticaria, food and drug allergy or allergic rhinitis), or any or all of the same proxy measures of atopy in adult life. Therefore, these variables were not included as confounders in the final models.

No association was observed between BMI7 z-score quartiles or BMI7 overweight and remitted asthma in either sex (results not shown).

\section{BMI32 and current asthma at $\mathbf{3 2}$ yrs of age}

At $32 \mathrm{yrs}$ of age, there were 125 (8.4\%) obese, 429 (28.7\%) overweight and 901 (60.3\%) normal-weight participants. Data were missing for $39(2.6 \%)$ individuals. There were more normal-weight females than males $(52.5 \%$ versus $47.5 \%$; $\mathrm{p}=0.04)$, more overweight males than females $(72.4 \%$ versus $27.6 \% ; \mathrm{p}<0.001)$ and there was no difference in the proportions of obese females and males ( $50.4 \%$ versus $49.6 \%$; $\mathrm{p}=0.90)$.

There was a significant trend across BMI32 quartiles for an association with adult-onset asthma only in females $(p=0.04)$, but when BMI32 quartiles were analysed further, there was a significant association only for the third quartile of BMI32 compared with the first (odds ratio (OR) (95\% CI) 4.73 (1.3616.46); $\mathrm{p}=0.01)$.

BMI7 and BMI32 were weakly correlated $(r=0.30, p<0.001)$. To investigate whether BMI7 was independently associated with asthma after adjusting for BMI32, BMI32 quartiles were tested as potential confounders of the associations between BMI7 z-score quartiles, BMI7 overweight and current asthma in females. There was a minor change (13\%) in trend across BMI7 quartiles for adult-onset asthma when BMI32 quartiles were introduced, with the trend estimate changing from OR $(95 \%$ CI) $1.73(1.17-2.57 ; \mathrm{p}=0.01)$ to $1.51(0.98-2.31 ; \mathrm{p}=0.06)$. There was a larger $(30 \%)$ change in the estimate for BMI7 overweight when BMI32 quartiles were introduced, with the estimate dropping from $3.05(1.28-7.29 ; p=0.01)$ to $2.13(0.82-5.57$; $\mathrm{p}=0.12$ ). Therefore, BMI32 quartiles were not included as a confounder in the final model for BMI7 quartiles, but were included in the final model for BMI7 overweight.

\section{Age at menarche, BMI7 and current asthma at 32 yrs of age}

Mean \pm SD age at menarche was $12.8 \pm 1.4$ yrs. The number attaining early menarche was 111 (16.8\%). A total of six $(5.4 \%)$ out of 111 developed current asthma between 7 and 21 yrs of age, while another six (5.4\%) developed current asthma after 21 yrs of age. Age at menarche and BMI7 were negatively correlated $(\mathrm{r}=-0.14, \mathrm{p}<0.001)$. There was a significant trend across quartiles of BMI7 z-scores for attaining early menarche (OR (95\% CI) 1.22 (1.01-1.47); p=0.04). Overweight compared with normal-weight young females at $7 \mathrm{yrs}$ of age were significantly more likely to attain early menarche (2.00 (1.223.29)). After adjusting for years of secondary schooling, age at

TABLE 2 Frequency distribution of incident asthma at 32 yrs of age by sex and asthma phenotype

\begin{tabular}{|c|c|c|c|c|}
\hline & \multicolumn{2}{|c|}{ Males with asthma ${ }^{\#}$} & \multicolumn{2}{|c|}{ Females with asthma ${ }^{\#}$} \\
\hline & Current asthma & Remitted asthma & Current asthma & Remitted asthma \\
\hline Subjects $n$ & 29 & 32 & 52 & 23 \\
\hline \multicolumn{5}{|c|}{ Age at onset yrs } \\
\hline $7-14$ & $8(13)$ & 19 (31) & $15(20)$ & $13(17)$ \\
\hline
\end{tabular}

Data are presented as $\mathrm{n}(\%)$, unless otherwise stated. In each case, the percentage value is calculated over the total number of same-sex individuals, i.e. with respect to 69 individuals in the male group and 75 individuals in the female group. ${ }^{\#}$ : starting after 7 yrs of age. 


\begin{tabular}{|c|c|c|c|c|}
\hline & \multicolumn{2}{|c|}{ Onset 7-21 yrs of age } & \multicolumn{2}{|c|}{ Onset after $21 \mathrm{yrs}$ of age } \\
\hline & Subjects n & OR (95\% Cl) & Subjects $n$ & OR $(95 \% \mathrm{Cl})$ \\
\hline BMI7 z-score & 25 & & 26 & \\
\hline Quartile 3 & 8 & $1.81(0.57-5.82)$ & 6 & $1.70(0.46-6.29)$ \\
\hline Quartile 4 & 4 & $0.95(0.24-3.69)$ & 13 & $3.86(1.20-12.42)$ \\
\hline Trend & & $1.01(0.70-1.47)^{\#}$ & & $1.73(1.17-2.17)^{\bullet}$ \\
\hline BMI7 overweight & 3 & $0.79(0.23-2.74)$ & 9 & $3.05(1.28-7.29)$ \\
\hline
\end{tabular}

OR: odds ratio; $\mathrm{Cl}$ : confidence interval. ${ }^{*}: p=0.94 ;{ }^{\natural}: p=0.01$

menarche was not associated with current asthma that developed between 7 and 21 yrs of age $(0.99(0.73-1.33) ; p=0.93)$ or after 21 yrs of age $(0.96(0.70-1.30) ; \mathrm{p}=0.78)$.

Early menarche adjusted for years of secondary schooling did not predict current asthma that developed between 7 and 21 yrs of age $(1.79(0.66-4.82) ; \mathrm{p}=0.25)$ or after $21 \mathrm{yrs}$ of age (1.79 (0.68-4.72); $\mathrm{p}=0.24)$. Early menarche was neither a confounder nor an effect modifier for BMI7 or BMI7 z-score quartiles and current asthma developing either between 7 and 21 yrs of age or after 21 yrs. Neither age of onset of menstruation nor early menarche was included in the final models.

\section{Lung function at 7 yrs of age, BMI7 and current asthma at 32 yrs of age}

Table 4 shows the associations between BMI7 and lung function at 7 yrs of age. BMI7 was positively associated with FEV1 and FVC in both sexes but negatively associated with FEV1/FVC ratio in females at 7 yrs of age.

Each $10-\mathrm{mL}$ increase in FEV1 and FVC was associated with a 3\% fall in risk of current asthma at 32 yrs of age $(p=0.03)$ in males whose asthma developed after 21 yrs of age. These associations were unchanged by the addition of BMI7 z-scores to the models.

FEV1 and FEV1/FVC ratio were then tested as potential confounders. For females, the addition of either FEV1 or FEV1/ FVC ratio as a covariate to models of current asthma regressed on
BMI7 produced a change in the estimates of $\leqslant 21 \%$. Therefore, FEV1 was included as a covariate in the final models.

\section{Multivariable models}

When adjusted for lung function at $7 \mathrm{yrs}$ of age, years of secondary education, adult smoking and BMI32, an association between BMI7 overweight and adult-onset current asthma at 32 yrs of age in females (OR (95\% CI) 3.05 (1.28-7.29)) was no longer observed (1.52 (0.48-4.86)). Adjustment for the same confounders did not alter the nonsignificant associations between BMI7 overweight and adolescent-onset asthma in either sex, or between BMI7 overweight and adult-onset asthma in males.

Models for the associations between BMI7 z-score quartiles and current asthma at 32 yrs of age with the different ages of onset are shown in table 5 .

In the adjusted model, the association between the highest quartile of BMI7 z-score and adult-onset current asthma in females remained significant as did the trend across quartiles of BMI7 z-score.

\section{DISCUSSION}

Among young females who were asthma free in the first 7 yrs of life, adiposity at 7 yrs of age was independently associated with current asthma at 32 yrs of age. Young females in the highest quartile of BMI7 z-scores were nearly four times as

\section{TABLE 4 Linear coefficients and 95\% confidence intervals $(\mathrm{Cl})$ for the association between body mass index and lung function at} 7 yrs of age

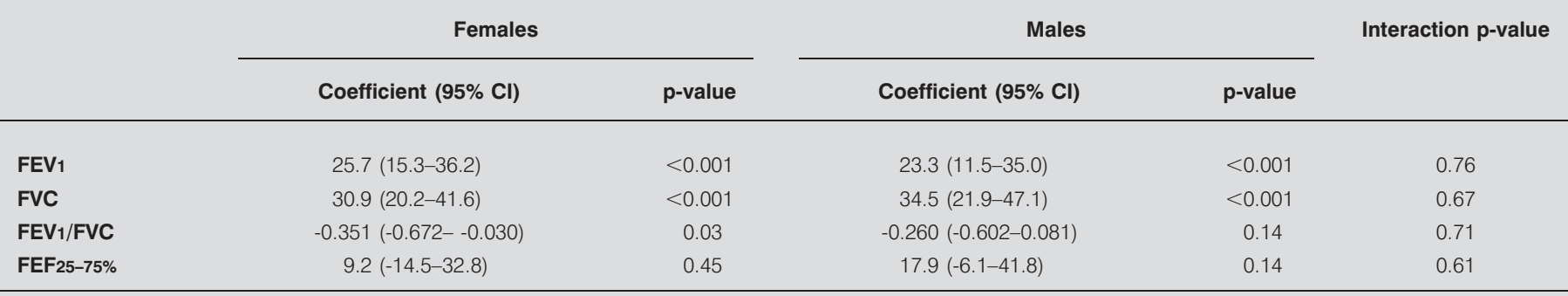

FEV1: forced expiratory volume in one second; FVC: forced vital capacity; FEF25-75\%: mean forced expiratory flow between 25 and $75 \%$ of FVC. 


\begin{tabular}{|c|c|c|c|c|c|}
\hline TABLE 5 & \multicolumn{5}{|c|}{$\begin{array}{l}\text { Crude and adjusted odds ratios (OR) with 95\% confidence intervals (Cl) for body mass index at } 7 \text { yrs of age (BMl7) } \\
\text { z-scores and current asthma at } 32 \mathrm{yrs} \text { of age }\end{array}$} \\
\hline \multirow[t]{2}{*}{ Asthma onset } & \multirow[t]{2}{*}{ BMI7 z-score } & \multicolumn{2}{|c|}{ Crude OR (95\% Cl) } & \multicolumn{2}{|c|}{ Adjusted $^{\#}$ OR (95\% Cl) } \\
\hline & & Females & Males & Females & Males \\
\hline \multirow[t]{4}{*}{$7-21$ yrs of age } & Quartile 1 & 1.00 & 1.00 & 1.00 & 1.00 \\
\hline & Quartile 4 & $0.95(0.24-3.69)$ & $0.28(0.03-2.55)$ & $1.59(0.36-6.96)$ & $0.27(0.03-2.60)$ \\
\hline & Trend across quartiles & $1.01(0.70-1.47)$ & $0.76(0.42-1.35)$ & $1.17(0.78-1.76)$ & $0.62(0.29-1.31)$ \\
\hline & $p$-value ${ }^{+}$ & 0.94 & 0.35 & 0.45 & 0.21 \\
\hline \multirow[t]{2}{*}{$>21 \mathrm{yrs}$ of $\mathrm{age}^{\mathrm{s}}$} & Quartile 1 & 1.00 & 1.00 & 1.00 & 1.00 \\
\hline & Quartile 2 & $0.76(0.16-3.51)$ & $2.97(0.76-11.64)$ & $0.48(0.09-2.75)$ & $3.24(0.79-13.26)$ \\
\hline
\end{tabular}

likely to present adult-onset current asthma at 32 yrs of age as those in the lowest quartile. The trend across quartiles was highly significant. Young females who were asthma free by 7 yrs of age and overweight had over three times the risk of adult-onset current asthma at 32 yrs of age compared with asthma-free normal-weight young females. However, this association was not independent when adjusted for BMI32, smoking at $32 \mathrm{yrs}$ of age, lung function at $7 \mathrm{yrs}$ of age and years of secondary schooling. No association was seen between adiposity at 7 yrs of age and adolescent-onset asthma, current at 32 yrs of age.

In males who were asthma free by 7 yrs of age, no association was observed for either of these exposures and current asthma at 32 yrs of age, whether it developed during adolescence or adult life. No association was observed in either sex for asthma that developed after 7 yrs of age and remitted by 32 yrs of age.

Childhood adiposity preceded asthma development in adult life and current at 32 yrs of age. The significant rising trend across quartiles of BMI7 z-score indicated a dose-response effect, supporting a causal relationship. The present results suggested that adiposity at 7 yrs of age in females who were asthma free to that age had the capacity to "programme" these females to develop asthma in adult life. Insufficient numbers prevented the analysis of the 7-14 and 15-21 onset-age groups separately. The present authors do not ascribe any special features to 21 yrs of age as a cut-point for assessing asthma risk compared with another age. While the analysis was constrained by the way the 1992 questionnaire was structured in terms of recalled age at onset of asthma (see Appendix 2), it was noted that 21 yrs of age corresponds approximately with the end of adolescence and may have biological importance.

Earlier cross-sectional studies have shown an association between high adult BMI and current asthma in females. The present study also found that higher BMI quartiles at 32 yrs of age were associated with current asthma at 32 yrs of age in females who were asthma free as children. However, the present results suggest that the risk observed at $32 \mathrm{yrs}$ of age may have begun with adiposity in childhood.

Mechanisms that could account for the association between childhood adiposity and increased risk of adult-onset asthma in females are unknown. While allergic mechanisms cause most childhood asthma, nonallergic mechanisms may be responsible in late-onset asthma. AARON et al. [31] showed a beneficial effect of weight loss on respiratory function for overweight females but not on bronchial hyperreactivity. This suggested that re-setting of airway mechanics, rather than atopy, may be responsible for respiratory symptoms in overweight females. The present results, which showed no confounding by atopy-related conditions, are consistent with non-atopic mechanisms.

GOLD et al. [32] suggested that adiposity in young females may be associated with a lower FEV1/FVC ratio, in turn associated with increased airway collapsibility. The present data showed similar FEV1/FVC ratio results in young females only, supporting this hypothesis. The current data also showed that FVC and FEV1 increased in young females as BMI7 increased, consistent with the findings of TANTISIRA et al. [33] and best explained by larger airway size compared with lung size in pre-pubertal young females [34].

Overweight and normal-weight individuals may have different lung mechanics [35]. Being overweight could lead to the "latch" state in airway smooth muscle and to increased airway resistance by producing small tidal volumes [36]. Obesity may induce increased bronchial hyperresponsiveness if deep inspiration occurs infrequently [37]. No data were available on static lung volumes, airway stiffness or bronchial hyperresponsiveness for the present 7 -yr-old participants. These mechanisms require further investigation.

Hormonal factors may contribute to symptoms, severity and morbidity of asthma in females $[23,38,39]$, consistent with the 
effects of gonadal hormones on immunity and the presence of lung oestrogen receptors [40, 41]. A significant trend was found across BMI7 quartiles for early menarche and a time lag was noted to late-onset asthma. Such findings suggest that higher childhood BMI leading to early menarche may initiate an endocrine insult, promoting an abnormal bronchial response to oestrogen that is magnified with continued exposure. However, in the present study, early menarche neither influenced current asthma nor confounded the association between higher BMI7 and adult-onset current asthma. As numbers were small, these negative results should be interpreted with caution.

Both cytokines and genetic factors may link obesity and asthma [42]. Leptin, tumour necrosis factor- $\alpha$, eotaxin and interleukin- 6 affect tissue inflammation and are secreted by adipose tissue [43]. A large twin study [44] showed that covariation between obesity and asthma was due to shared genetic factors. Polymorphisms in the $\beta_{2}$-adrenergic receptor gene have been associated with both asthma and obesity $[45,46]$.

The major strength of the current study is its longitudinal nature spanning childhood and early adult life, allowing observation of relationships between childhood measurements, such as BMI and lung function, and later-life asthma. Whilst BMI is the usual measure of adiposity in children [47], greater precision is achieved if that individual's BMI is assessed relative to a reference population of the same age and sex. This was the case in the present study, lending it added strength. Additional strengths were the availability of measured height and weight, hence the accurate estimates of childhood BMI, and the availability of lung function and age at menarche.

The present study has limitations. The response rate to the mailed questionnaire in 1992 was $87 \%$. Nonresponders were known to be evenly distributed according to asthma status by 7 yrs of age; however, whether they were more or less likely than responders to have current asthma at $32 \mathrm{yrs}$ of age remains unknown. It seems unlikely that nonresponse would seriously bias the study since the number of nonresponders was small. The present authors' definition of asthma used a history of asthma or wheeze-ever. This must have led to the inclusion of children with wheeze related to infection and thus it is possible that over-diagnosis of asthma was present in the parent-completed questionnaire. However, such an error would only be important if it were differential across both weight groups and sex, which seems unlikely. Others have found that this definition compares well with one including bronchial hyperresponsiveness [48, 49], and a looser definition shifts the estimates towards the null [20]. The use of diagnosed asthma may result in under-diagnosis $[50,51]$. Finally, the TAS questionnaire had been validated against respiratory physicians' diagnosis for asthma in the previous 12 months [49]. It was noted that the number of individuals with adult-onset asthma, current at 32 yrs of age, was modest, particularly in males. It is possible that the absence of any association in males may be related to lack of statistical power. It was observed that the present cohort of 7-yr-old children was more adipose and showed less BMI variability than the reference population (table 1). This disparity may have been due to the Tasmanian population in 1968 consisting of a homogeneous group of Anglo-Celtic individuals, differing ethnically from the American population of reference.
In conclusion, the present study provides evidence of an association, observed only for females, between body mass index at $7 \mathrm{yrs}$ of age and current asthma in adult life that developed after 21 yrs of age. The current results suggest that childhood adiposity may be important in the development of late-onset asthma. Therefore, attempts to reduce the burden of excess weight in society must be supported emphasising the need to focus on children, perhaps young females particularly, in order to prevent asthma. Body mass index data in the present cohort were gathered in 1968. There is no doubt that the prevalence of overweight among young females in Australia has since increased [7, 52, 53]. Presently, there may be an even greater risk of asthma in females who were adipose at a younger age than was the case in 1991-1993.

\section{REFERENCES}

1 Woolcock AJ, Peat JK. The rising trends in asthma. Ciba Foundation Symposium 206. London, John Wiley \& Sons, 1997; pp. 122-139.

2 Mannino DM, Homa DM, Pertowski CA, et al. Surveillance for asthma-United States, 1960-1995. MMWR CDC Surveill Summ 1998; 47: 1-27.

3 Beasley R, Crane J, Lai CK, Pearce N. Prevalence and etiology of asthma. J Allergy Clin Immunol 2000; 105: S466S472.

4 Worldwide variation in prevalence of symptoms of asthma, allergic rhinoconjunctivitis, and atopic eczema, ISAAC. The International Study of Asthma and Allergies in Childhood (ISAAC) Steering Committee. Lancet 1998; 351: 1225-1232.

5 Obesity: preventing and managing the global epidemic. Report of a WHO consultation. World Health Organ Tech Rep Ser 2000; 894: i-xii, pp. 1-253.

6 Flegal KM, Troiano RP. Changes in the distribution of body mass index of adults and children in the US population. Int J Obes Relat Metab Disord 2000; 24: 807-818.

7 Booth ML, Chey T, Wake M, et al. Change in the prevalence of overweight and obesity among young Australians, 1969-1997. Am J Clin Nutr 2003; 77: 29-36.

8 Booth ML, Wake M, Armstrong T, Chey T, Hesketh K, Mathur S. The epidemiology of overweight and obesity among Australian children and adolescents, 1995-97. Aust N Z J Public Health 2001; 25: 162-169.

9 Shaheen SO, Sterne JA, Montgomery SM, Azima H. Birth weight, body mass index and asthma in young adults. Thorax 1999; 54: 396-402.

10 Luder E, Ehrlich RI, Lou WY, Melnik TA, Kattan M. Body mass index and the risk of asthma in adults. Respir Med 2004; 98: 29-37.

11 Gennuso J, Epstein LH, Paluch RA, Cerny F. The relationship between asthma and obesity in urban minority children and adolescents. Arch Pediatr Adolesc Med 1998; 152: 1197-1200.

12 Figueroa-Muñoz JI, Chinn S, Rona RJ. Association between obesity and asthma in 4-11 year old children in the UK. Thorax 2001; 56: 133-137.

13 von Mutius E, Schwartz J, Neas LM, Dockery D, Weiss ST. Relation of body mass index to asthma and atopy in children: the National Health and Nutrition Examination Study III. Thorax 2001; 56: 835-838. 
14 Schachter LM, Peat JK, Salome CM. Asthma and atopy in overweight children. Thorax 2003; 58: 1031-1035.

15 Gilliland FD, Berhane K, Islam T, et al. Obesity and the risk of newly diagnosed asthma in school-age children. Am J Epidemiol 2003; 158: 406-415.

16 Guerra S, Sherrill DL, Bobadilla A, Martinez FD, Barbee RA. The relation of body mass index to asthma, chronic bronchitis, and emphysema. Chest 2002; 122: 12561263.

17 Chen Y, Dales R, Tang M, Krewski D. Obesity may increase the incidence of asthma in women but not in men: longitudinal observations from the Canadian National Population Health Surveys. Am J Epidemiol 2002; 155: 191-197.

18 Chinn S, Rona RJ. Can the increase in body mass index explain the rising trend in asthma in children? Thorax 2001; 56: 845-850.

19 Xu B, Pekkanen J, Laitinen J, Jarvelin MR. Body build from birth to adulthood and risk of asthma. Eur J Public Health 2002; 12: 166-170.

20 Camargo CA Jr, Weiss ST, Zhang S, Willett WC, Speizer FE. Prospective study of body mass index, weight change, and risk of adult-onset asthma in women. Arch Intern Med 1999; 159: 2582-2588.

21 Beckett WS, Jacobs DR Jr, Yu X, Iribarren C, Williams OD. Asthma is associated with weight gain in females but not males, independent of physical activity. Am J Respir Crit Care Med 2001; 164: 2045-2050.

22 Herrera-Trujillo M, Barraza-Villarreal A, Lazcano-Ponce E, Hernandez B, Sanin LH, Romieu I. Current wheezing, puberty, and obesity among Mexican adolescent females and young women. J Asthma 2005; 42: 705-709.

23 Varraso R, Siroux V, Maccario J, Pin I, Kauffmann F. Asthma severity is associated with body mass index and early menarche in women. Am J Respir Crit Care Med 2005; 171: 334-339.

24 Zapletal A, Paul T, Samanek M. [Significance of contemporary methods of lung function testing for the detection of airway obstruction in children and adolescents]. Z Erkr Atmungsorgane 1977; 149: 343-371.

25 Pulkki L, Keltikangas-Jarvinen L, Ravaja N, Viikari J. Child-rearing attitudes and cardiovascular risk among children: moderating influence of parental socioeconomic status. Prev Med 2003; 36: 55-63.

26 Sharma S, Malarcher AM, Giles WH, Myers G. Racial, ethnic and socioeconomic disparities in the clustering of cardiovascular disease risk factors. Ethn Dis 2004; 14: 43-48.

27 Cole TJ. The LMS method for constructing normalized growth standards. Eur J Clin Nutr 1990; 44: 45-60.

28 Kuczmarski RJ, Ogden CL, Grummer-Strawn LM, et al. CDC growth charts: United States. Adv Data 2000; 314: 1-27.

29 Cole TJ, Bellizzi MC, Flegal KM, Dietz WH. Establishing a standard definition for child overweight and obesity worldwide: international survey. BMJ 2000; 320: 12401243.

30 Kirkwood B, Sterne J. Essential Medical Statistics. 2nd Edn. Malden, Blackwell Science Ltd, 2003.

31 Aaron SD, Fergusson D, Dent R, Chen Y, Vandemheen KL, Dales RE. Effect of weight reduction on respiratory function and airway reactivity in obese women. Chest 2004; 125: 2046-2052.
32 Gold DR, Damokosh AI, Dockery DW, Berkey CS. Bodymass index as a predictor of incident asthma in a prospective cohort of children. Pediatr Pulmonol 2003; 36: 514-521.

33 Tantisira KG, Litonjua AA, Weiss ST, Fuhlbrigge AL. Association of body mass with pulmonary function in the Childhood Asthma Management Program (CAMP). Thorax 2003; 58: 1036-1041.

34 Becklake MR, Kauffmann F. Gender differences in airway behaviour over the human life span. Thorax 1999; 54: 11191138.

35 Fung KP, Lau SP, Chow OK, Lee J, Wong TW. Effects of overweight on lung function. Arch Dis Child 1990; 65: 512-515.

36 Tantisira KG, Weiss ST. Complex interactions in complex traits: obesity and asthma. Thorax 2001; 56: Suppl. 2, ii6473.

37 Skloot G, Permutt S, Togias A. Airway hyperresponsiveness in asthma: a problem of limited smooth muscle relaxation with inspiration. J Clin Invest 1995; 96: 23932403.

38 Eliasson O, Scherzer HH, DeGraff AC Jr. Morbidity in asthma in relation to the menstrual cycle. J Allergy Clin Immunol 1986; 77: 87-94.

39 Skobeloff EM, Spivey WH, Silverman R, Eskin BA, Harchelroad F, Alessi TV. The effect of the menstrual cycle on asthma presentations in the emergency department. Arch Intern Med 1996; 156: 1837-1840.

40 Grossman CJ. Interactions between the gonadal steroids and the immune system. Science 1985; 227: 257-261.

41 Mendelson CR, MacDonald PC, Johnston JM. Estrogen binding in human fetal lung tissue cytosol. Endocrinology 1980; 106: 368-374.

42 Beuther DA, Weiss ST, Sutherland ER. Obesity and asthma. Am J Respir Crit Care Med 2006; 174: 112-119.

43 Fantuzzi G. Adipose tissue, adipokines, and inflammation. J Allergy Clin Immunol 2005; 115: 911-919; quiz 920.

44 Hallstrand TS, Fischer ME, Wurfel MM, Afari N, Buchwald D, Goldberg J. Genetic pleiotropy between asthma and obesity in a community-based sample of twins. J Allergy Clin Immunol 2005; 116: 1235-1241.

45 Hall IP, Wheatley A, Wilding P, Liggett SB. Association of Glu $27 \beta_{2}$-adrenoceptor polymorphism with lower airway reactivity in asthmatic subjects. Lancet 1995; 345: 12131214.

46 Ishiyama-Shigemoto S, Yamada K, Yuan X, Ichikawa F, Nonaka K. Association of polymorphisms in the $\beta_{2^{-}}$ adrenergic receptor gene with obesity, hypertriglyceridaemia, and diabetes mellitus. Diabetologia 1999; 42: 98-101.

47 Dietz WH, Bellizzi MC. Introduction: the use of body mass index to assess obesity in children. Am J Clin Nutr 1999; 70: 123S-125S.

48 Remes ST, Pekkanen J, Remes K, Salonen RO, Korppi M. In search of childhood asthma: questionnaire, tests of bronchial hyperresponsiveness, and clinical evaluation. Thorax 2002; 57: 120-126.

49 Jenkins MA, Clarke JR, Carlin JB, et al. Validation of questionnaire and bronchial hyperresponsiveness against respiratory physician assessment in the diagnosis of asthma. Int J Epidemiol 1996; 25: 609-616. 
50 Silver EJ, Crain EF, Weiss KB. Burden of wheezing illness among US children reported by parents not to have asthma. J Asthma 1998; 35: 437-443.

51 Panhuysen CI, Bleecker ER, Koeter GH, Meyers DA, Postma DS. Characterization of obstructive airway disease in family members of probands with asthma. An algorithm for the diagnosis of asthma. Am J Respir Crit Care Med 1998; 157: 1734-1742.

52 Vaska V, Volkmer R. Increasing prevalence of obesity in South Australian 4-year-olds: 1995-2002. J Paediatr Child Health 2004; 40: 353-355.

53 Magarey AM, Daniels LA, Boulton TJ, Cockington RA. Predicting obesity in early adulthood from childhood and parental obesity. Int J Obes Relat Metab Disord 2003; 27: 505 513.

\section{APPENDIX 1: EXTRACT FROM THE 1968 PARENT- COMPLETED QUESTIONNAIRE FOR THE CHILD'S MEDICAL HISTORY.}

1. Has he or she at any time in his or her life suffered from attacks of asthma or of wheezy breathing? (Note: Please regard "asthma" and "wheezy breathing" as being much the same thing for this survey; we do not ask you to try to tell the difference.)

2. How long is it since the last attack?

3. On average (as near as you can say), how often do these attacks tend to occur (over the last 2 years or so)?

4. At what age did these attacks begin?

5. Since the attacks began, approximately how many has he or she had altogether?

6. Does he or she get attacks of "hay fever" (that is, sneezing, running or blocked nose, sometimes with itchy eyes or nose)?

7. Did he or she have infantile (baby) eczema?

8. Has he or she ever had eczema in the creases (bends) of elbows, wrists or knees?
9. Have you been told by a doctor that he/she is allergic to any foods or medicines?

10. Does he/she get hives?

\section{APPENDIX 2: EXTRACT FROM THE 1991-1993 QUESTIONNAIRE COMPLETED BY THE 32-YR-OLD PARTICIPANTS.}

1. Have you at any time in your life suffered from attacks of asthma or wheezy breathing?

2. At what age did the attacks begin?

a) Under 7 years

b) Between 7 and 14 years

c) Between 15 and 21 years

d) Over 21 years

3. How long is it since the last attack?

a) Less than a month ago

b) Over one but less than three months ago

c) Over three but less than six months ago

d) Over six but less than twelve months ago

e) Over one year but less than two years ago

f) Over two years

g) Over five years ago

h) Over ten years ago

4. The following is a list of medications. For each medication please indicate "YES" or "NO" depending on whether you have used it in the last two weeks.

a) Cough medicines or any other remedies for colds?

b) Medications for asthma or wheeze?

c) Medications for an allergy?

5. Do you get eczema?

6. Do you get hives?

7. Have you ever been told by a doctor that you are allergic to any foods or medicines?

8. Do you get attacks of "hay fever" (that is, sneezing, running or blocked nose, sometimes with itchy eyes or blocked nose)? 